\title{
Who Wins and Who Loses from Staple Food Price Spikes? Welfare Implications for Mozambique
}

\author{
Javier E. Baez, German Caruso, and Hemant Pullabhotla ${ }^{1}$
}

Changes in food prices -triggered frequently by natural disasters, macroeconomic shocks or regional market disruptions-can lead to large household welfare effects. At over 60 and 40 percent, food budget shares remain high in rural and urban Mozambique, respectively. Furthermore, nearly 70 percent of the population depends on agriculture for their livelihoods. To determine the net impact of food price changes on consumption and poverty, we performed incidence analysis combining household and farmer survey data with disaggregated, market-level price data on major staples (maize, rice, and cassava). Overall, we find evidence for a large net negative welfare effect of price rises in rural areas, and a small, negative effect in the urban areas. For instance, $A 10$ percent increase in maize prices is associated with an average reduction of 1.2 percent in consumption per capita in rural areas and 0.2 percent in urban areas. Not all households are affected equally. Overall, the negative impacts are larger for the bottom half of the distribution. As a result, the sharp food price spike observed in 2016-17 may have translated into a poverty increase of 4-6 percentage points, with some of the poorest provinces bearing much of the brunt. These findings underscore the importance of improving the functioning of agricultural input and output markets, developing early food security warning systems, and increasing the availability of rapidly scalable safety nets.

Mozambique is highly exposed to frequent food price spikes. As seen in Figure 1, food as well as other goods and services such as fuel and electricity saw large price increases across the country from 20152017. Food price increases are especially important to understand, as most Mozambican households depend on agriculture for their livelihoods. Because of many unexpected shocks, including weather disasters, pests, and international market pressures, the country's food prices increased an average of 40 percent between 2016 and 2017, and prices in some provinces even increased by 180 percent. However, broadly speaking, food price changes might cause both negative and positive effects for households depending on their net food consumption status. In other words, there are "winners" and "losers" from changes in food prices. In order to keep their calorie intake constant, consumers (net buyers) might have to buy cheaper food or re-allocate money intended for other goods. In contrast, food sellers (net sellers) might see an increase in their profits if everything else remains constant. Since the country might continue being exposed to large changes in food prices in the future because of climate change and natural disasters -among other factors, the impacts of food price inflation must be better understood.

\footnotetext{
${ }^{1}$ This note summarizes the key findings of a larger working paper: Baez Ramirez, Javier Eduardo; Caruso, German Daniel; Pullabhotla, Hemant Kumar. 2018. "Who Wins and Who Loses from Staple Food Price Spikes? Welfare Implications for Mozambique (English)". World Bank Policy Research working paper; no. WPS 8612. Washington, D.C. (c) World Bank.
} 
Figure 1. Mozambique saw steep food price inflation in 2016, going up as high as $\mathbf{4 0}$ percent

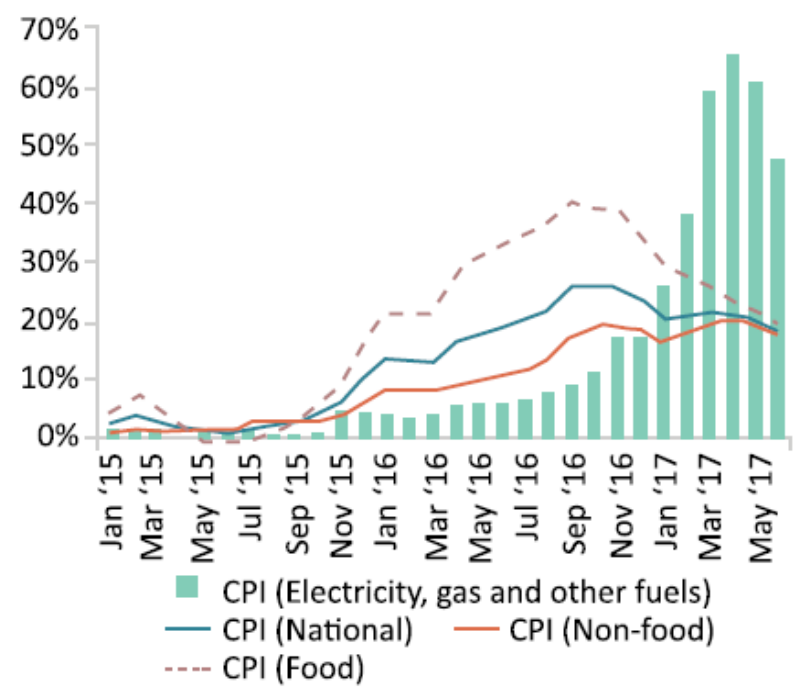

Source: INE. Taken from "Mozambique Economic Update: A Two Speed Economy" (World Bank, 2017)

\section{Methodology and Data to Measure Price Shock Effects Across Mozambique}

How much do price shocks in Mozambique impact household welfare? Are households in different locations more, or less vulnerable? Many researchers drawn to the effects of the 2007-2008 global price spikes found how Mozambique was vulnerable to the effects of price shocks. For instance, some studies found that domestic prices for staple goods remain high in the country after international prices had declined, and that there was high volatility in retail markets before and during price spikes in multiple countries. This study uses both consumption data from households and production data from smallholders to analyze the net household welfare effects (consumption per capita) of food price shocks at the national, regional, and province levels. The analysis focuses on maize, cassava, and rice, which make up more than 30 percent of the average food budget share of a typical Mozambican household. The findings hold when multiple robustness tests
Figure 2: Food represents a large share of total of household consumption, even in urban areas

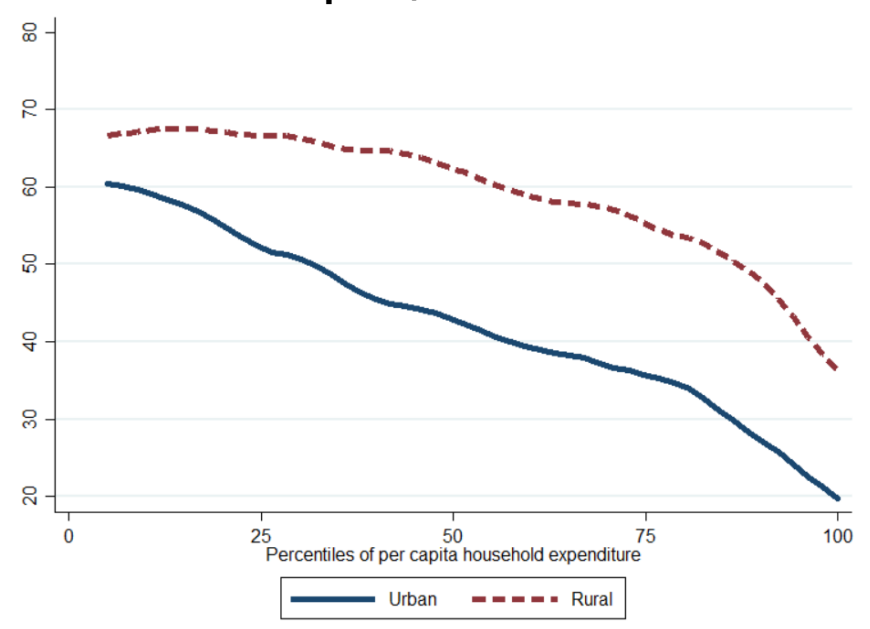

Source: World Bank calculations based on IOF-2014/15

were conducted, including matching household consumption and farmers production data at different spatial distances and varying the relative size of the increase in food prices on producers. Since the analysis does not account for potential production and consumption behavioral responses caused by changes in food prices, the findings should be interpreted as short-run estimates only.

\section{Broad Loss, Diverse Impacts}

Food consumption patterns reveal that poorer Mozambican households can be highly vulnerable to price shocks. Mozambican households spend a high share of their budgets on food: an average of 56 percent of the household budget goes towards food. Figure 2 shows that households who have less to spend allocate a larger share of their consumption to food, both in rural and urban areas. The food budget share also varies widely across geographic locations. Food consumption forms a higher percentage of overall consumption in rural areas and Northern regions of the country -where the levels of poverty are higher, and a lower percentage in the Southern regions and cities. For instance, 72.1 percent of the 
total consumption of an average household from the Niassa province (amongst the provinces with the highest poverty rates) in the north is allocated to food, while in Maputo Cidade (the capital city) this share falls to 31 percent. Overall, food consumption shares across the country are high; households in seven of the eleven provinces in the country use over half of their budget on food, and the food shares in cities in the northern provinces are over 50 percent.

Households are differently impacted based on staple type, location, and level of poverty. Overall, the simulations show that a 10 percent increase in maize prices causes a loss of 1.2 percent of household consumption per person in the rural areas and 0.2 percent in urban areas. Partly due to their lower weight in the food basket, price increases of both rice and cassava lead to smaller consumption losses: households lose 0.2 percent in both rural and urban areas because of a 10 percent increase in rice prices, and they lose 0.4 percent in rural areas and 0.1 in urban areas because of a similar increase in cassava prices. When accounting for the combined net welfare impact of the actual increase in prices of the three staples in the period 2014-2016 (89 percent for maize, 37 percent for cassava and 22 percent for rice), the average reduction in household consumption adds up to 11.7 percent in rural areas and 2.7 percent in urban areas. However, the impact of the price shocks varies greatly across provinces. Households experience the largest welfare losses in the provinces of Niassa, Tete, Manica, and Sofala, some of the poorest regions of the country, which see a net effect of over 20 percent lost consumption. However, some more urbanized areas like Maputo Province and the capital city, Maputo Cidade, only see a net loss of less than 0.83 percent

\section{Figure 3: The negative welfare impacts of food price} inflation increased poverty across the country

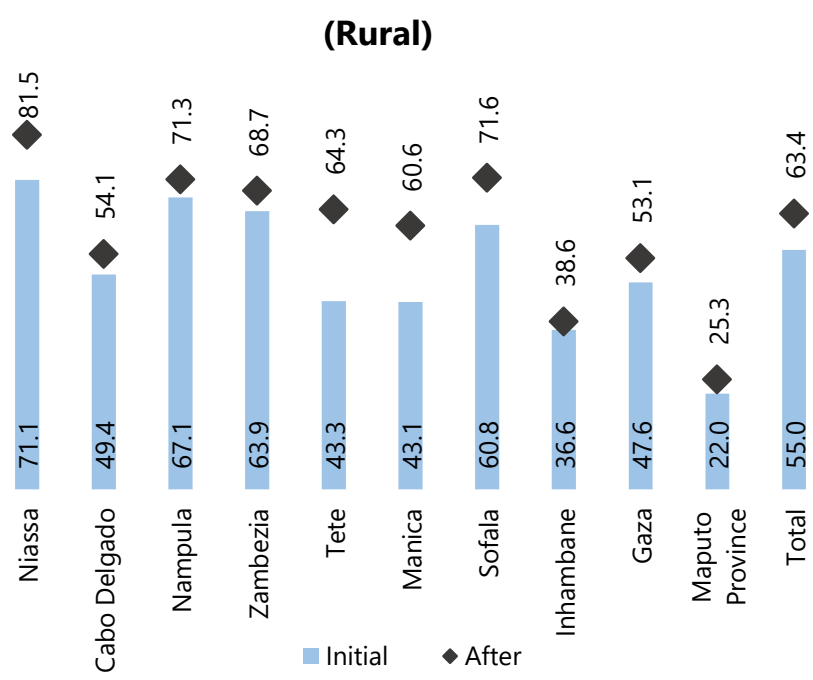

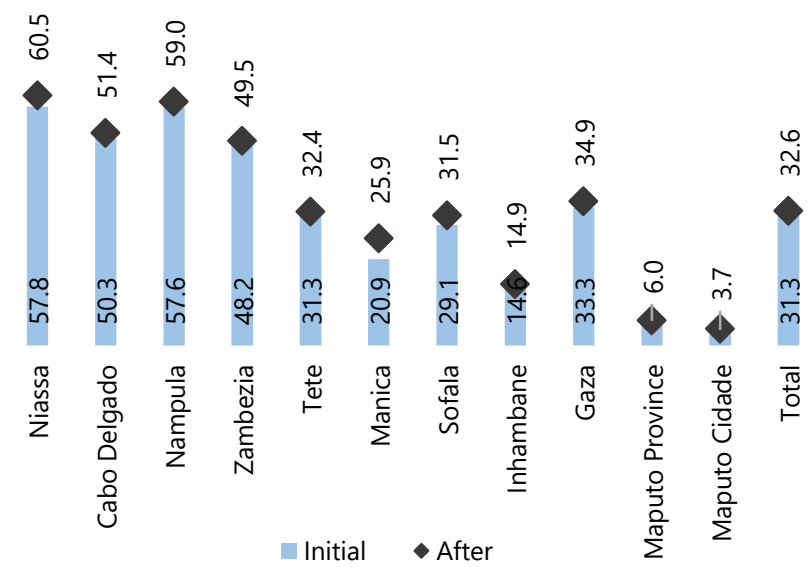

Note: simulations of the first order effects of increases in the prices of maize, rice and cassava (2014-16) on poverty headcount rates. Initial = before price increase. After = after price increase. Source: World Bank calculations based on IOF-2014/15

Overall, the net reduction on consumption brought about by the 2016-17 food price spikes is expected to have increased the number of people in poverty Though the negative effects are felt at all levels of income in the country, households at different levels of income feel the shock to varying degrees. In rural households, those most affected by the price shock are not the poorest, but those closer to the poverty line. In urban areas, the largest losses are from the absolute poorest households in the country. Due to 
the spike, the poverty headcount increased in the country by 5.9 percentage points; rural areas experience a poverty increase of 8.5 percentage points, and urban areas increased the poverty headcount by 1.34 percentage points. The most substantial increase was in the rural areas of the Tete province, where the fraction of people in poverty could have increased by close to 19 percentage points. Figure 3 shows estimates of the increase in poverty both in rural and urban areas across provinces, confirming the high levels of regional heterogeneity in changes in household welfare.

\section{How Can Mozambique Reduce Food Price Volatility and its Household Welfare Effects?}

Several policy options are available to reduce food price fluctuations and the vulnerability of households to large price shocks. The effects of food price spikes in Mozambique are mostly felt by low-income households in poorer regions, which at the same time are also highly exposed and vulnerable to other types of shocks. Minimizing these losses requires action across several policy areas, including of course comprehensive risk management policies.

To do this, Mozambique must increase the resilience of agriculture to weather shocks and other risks, like pests, and allow trade within the country and across borders during these high-price periods. Second, countries must make sure local agricultural markets are more efficient, by investing in better connectivity and get better information on prices to farmers and consumers. This will improve the markets' ability to reflect the agriculture's value, will reduce costs of producing and marketing the food, and will reduce price volatility. Also, the country should invest in early warning systems that track food security, food prices, and rainfall across the country. In conjunction with improving the functioning of agricultural markets, long-term efforts to diversify household diets are required to reduce reliance on staples to meet calorie and nutrition needs. Finally, scalable safety net policies are essential to ensure that individuals can experience minimally acceptable standards of living after the shocks occur. The insights offered by this research can help to target and prioritize the implementation of such programs to benefit the most vulnerable households in Mozambique.

\section{ABOUT THE AUTHORS}

Javier E. Baez is a Senior Economist at the World Bank's Poverty and Equity Global Practice and a Research Fellow at the Institute of the Study of Labor (IZA).jbaez@worldbank.org

German Caruso is an Economist at the World Bank's Poverty and Equity Global Practice.

gcaruso@worldbank.org

Hemant Pullabhotla is a Graduate Student in Agricultural and Consumer Economics at the University of Illinois. pullabh2@illinois.edu 